\section{New Instruments and Suggestions}

\section{TECHNIC FOR MAKING THE SUPRAPUBIC "STAB WOUND"}

Francis Reder, M.D., St, Louis

The suprapubic "stab wound" is one of the most efficient and most satisfactory methods of draining the abdominal cavity. Such drainage is imperatively indicated in septic conditions with their concomitant pus accumulations. Patients who are to be subjected to an operative measure for the

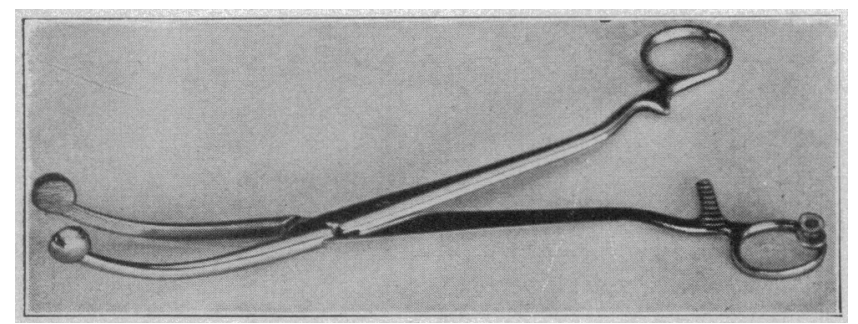

Fig. 1.-Ball-end forceps open.

relief of a septic peritonitis are usually very ill, and consequently poor operative risks. The surgeon keenly appreciates every minute of the time his patient is on the operating table.

A suprapubic stab should be clean-cut; injury to any underlying viscus must not occur. The peeling off of the parietal peritoneum from the abdominal wall during the attempt to penetrate it must be avoided. Such traumatism creates an additional absorption area. Iastly, the directing finger of the operator, which is usually introduced into the abdominal cavity to "see" that no important viscus is concealed at the point of the stab and to steady the tissues where the point of the knife is to penetrate, must not be pricked, lest an infection result.

To facilitate the establishing of a suprapubic stab wound and to obviate any danger of the operator pricking his

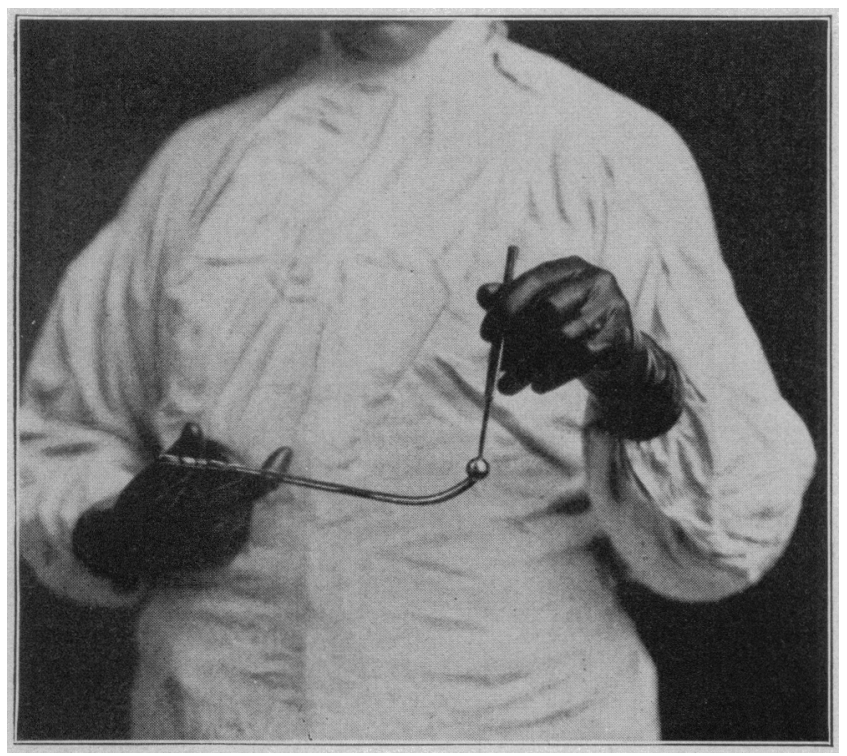

Fig. 2.-Showing point of knife caught in ball-end of forceps, a convenient method of enlarging the stab wound.

directing finger during its performance, a heavy forceps of good length-a pedicle forceps about 12 inches in length has answered the purpose admirably-that it may be readily manipulated with a firm grasp, and having a ball of soft metal, the size of an ordinary marble fused at the end, has proved a satisfactory aid. With it the "stab wound" can be made quickly and without danger to any viscus.
The technic is simple. Introducing the forceps through the abdominal wound into the abdomen, the ball-end of the forceps is firmly pressed against the point of the abdominal wall where the suprapubic "stab wound" is to be placed. With a knife, an incision is made down on the ball-end of the forceps. The incision should be sufficiently large to accommodate the drainage tube. As soon as the peritoneum is reached, pressure upward with the forceps will force the ball-end, covered with the peritoneum, into the incision. The peritoneum is easily incised on the ball, and the stab wound is made. The ball-end of the forceps is now gently pressed into the wound, and the blades of the forceps are spread sufficiently far apart to allow the ball-end to grasp the drainage tube. In this manner the drainage tube can be easily drawn into the abdominal cavity.

Should the stab wound prove too small it can without difficulty be enlarged by having the ball-end of the forceps, while in situ, catch the point of the knife, and with a gentle sawing motion safely and readily create a wound of any desired size.

\section{AN IMPROVED BREAST-MILK COLLECTOR}

Julius H. Hess, M.D., Chicago

This milk collector has been devised for use by wetnurses and mothers who have to feed premature and debilitated infants who are too weak to nurse at the breast.

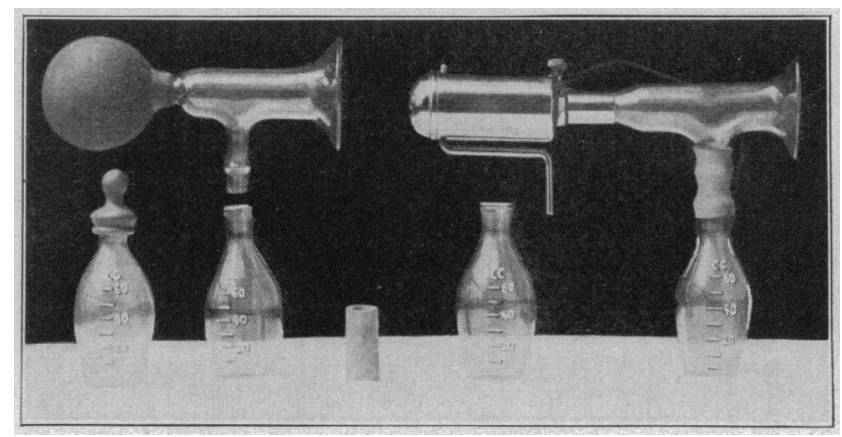

Imiproved breast-milk collector.

The collector is of great value for use when the nurse is unable to express the milk by hand, which is not infrequently the case in private practice.

The pump is made in two types, the first fitted with a large rubber bulb of a size considerably larger and of better quality than is ordinarily sold with a breast pump, and, second, with an attachment to which the Holz vacuum pump can be fitted. In place of the ordinary collecting bulb at the lower surface, an arm is so constructed as to allow the milk to drain into it and pass directly into specially designed graduated 2-ounce milk flasks. The neck of these flasks is of the proper size to take the ordinary nursing nipple. The lower half of the pump drain is made to fit on the inside of the nursing bottles, and an air tight contact is produced by a heavy piece of rubber tubing which is first slipped over the neck of the bottle and then pushed up over the pumpdrain until the small flange in the center of the latter rests on the neck of the bottle. This flange and one at the rim of the bottle's neck allow a good firm contact between the pump and the nursing bottle, so that there is no danger of the bottle falling away from the pump.

\section{ADVANTAGES}

Any number of bottles can be purchased with a single pump, and individual feedings can be collected and set aside for future use, in required amounts. The milk passes directly from the pump into the flasks without reaching the air and coming into contact only with glass surfaces which are so constructed as to allow of easy cleansing.

The apparatus can be obtained from Sharp and Smith, 155 North Michigan Avenue, Chicago.

5514 Indiana Avenue. 